\begin{tabular}{|c|c|}
\hline & Asian Social Work Journal (ASWJ) \\
\hline $\begin{array}{c}\text { ASIAN SOCIAL WORK } \\
\text { JOURAL } \\
\text { (ASW) }\end{array}$ & Volume 4, Issue 3, July 2019 \\
& e-ISSN : 0128-1577 \\
& Journal home page: \\
& www.msocialwork.com \\
\hline
\end{tabular}

\title{
"Oh God, Please Save Us from War": AN Ethography Study of Impact of War on Health Among Syrian Children Refuges in Lebanon and Their Experience Living with Health Problems
}

\author{
Zulkhairul Naim Sidek Ahmad ${ }^{1}$, Burhanudin Busu ${ }^{2}$ \\ 1Department Community and Family Medicine, Faculty of Medicine and Health Sciences, Universiti Malaysia Sabah \\ (UMS) \\ 2Department of Trauma and Orthopaedics, King College Hospital, United Kingdom \\ Corrrespondence: Zulkhairul Naim Sidek Ahmad (zknaeim85@gmail.com)
}

\begin{abstract}
In nearly six years of armed conflict, more than 250,000 Syrians have lost their lives and there were over 1 million Syrian refugees who had been registered in Lebanon in 2016. It has been reported that exposure to war causes injury, illness and breakdown in the health care structures especially to children. This paper attempts to evaluate the impact of war on health in children and to explore their experience living with health problems. A qualitative data from semi structured interview was conducted among mothers in refugee camp in Bekaa Valley, Lebanon Participants were purposefully sampled and asked to share their impact on war to health of their children. All interviews were written manually and analysed thematically. Ten participants were involved in this study. There were three main themes were identified, each of which led to health risks for the children; antepartum, intrapartum and postpartum. There was variety of health problems reported ranging from neurological, musculoskeletal disorder to ocular problems. The experience living with health problems were understood through construction of three thematic categories emerged; psychological burden, disruption of daily living and economic effect. In additional, the participants also highlighted the intergenerational impact of war on health predominantly mental disorder, congenital abnormalities, infectious disease and complication in pregnancy. In general, this paper provides an important understanding of impact of wars on health among vulnerable group which is children. The effects of wars on health and health care services are substantial. All these issues should be explored more to ensure the children received adequate health care. The results generated form this study can inspire new collaboration with many authorities in the design and implementation intervention to improve health status in war zone.
\end{abstract}

Key words: war, health, health care systems, children, refugees

\section{Introduction}

World Health Organization defined conflicts or wars as the instrumental use of violence by people who identify themselves as members of a group - whether this group is transitory or has a more permanent identity - against another group or set of individuals, in order to achieve political,economic or social objectives. Wars are armed conflicts with more than 1,000 battle-related deaths in any one year ("WHO | World report on violence and health," 2015). 
In 2001 and 2010, there were 69 armed conflicts involving at least one state and 221 non-states and 127 actors were involved one-sided violence that resulted in more than 25 people death in a year in each sided and today, the civil war in Syria is one of the most deadly in the world ("SIPRI Yearbook 2012: Armaments, Disarmament and International Security, Summary," 2012). In Lebanon, they are estimate 4.5 million citizens and the prevalence of Syria refugee in Lebanon is $25 \%$. Since Syria conflict in 2011, more than 250,000 Syrians have lost their lives and there are 1.1 million Syrian refugees who had been registered with the United Nation High Commissioner for Refugees (UNHCR) in Lebanon in 2016 and many of them living in informal tented settlements scattered around the country (MERCY CORPS, 2016).

There is substantial evidence for the harmful consequences of war on health. These effects can be divided into direct and indirect effects (Pedersen, 2002)(Santa Barbara, 2006). The direct effects are the mortality and morbidity associated with conflict and indirect effects which include disruption of health care and displacement of families (Goldson, 1996). Despite of that, they also destroy property, increase crime and homicide as well as disrupt economic activity (Pedersen, 2002). In $20^{\text {th }}$ century, four of every hundred people died from war related causes either direct or indirect and this may be the result of warfare tactics (Richard M. Garfield \& Alfred I. Neugut, 2000).

In a study conducted by Davis et al, during conflict in Africa, the infant mortality rate increased by 12 per thousand and the life expectancy reduce by more than 2 years (David D \& J.Kuritsky, 2002).

In the past 10 years, approximately four million people in war zones have been permanently disabled and a large proportion of them are children (Southall \& Carballo, 1996). Exposure to war can be traumatic in its own right. Indeed, study also shows that refugees exposed to prolong war are about 10 times more likely to have post-traumatic stress disorder than general populations. This disorder remains an untreated especially in children (Fazel, Wheeler, \& Danesh, 2005). In additional, common preventable diseases that causes of death in children during conflict; ranked as pneumonia, gastroenteritis, malaria, measles, HIV and landmines (Pearn, 2003). Public health prevention activities such as immunization and health care surveillance systems can be substantially disturbed and this what really happened in Rwanda, Sudan, Liberia, Chechnya and Iraq (Hynes,2002.).

In summary, there is substantial evidence from research suggests that the health effects during civil wars are relatively know. However, less known is in qualitative study and in Lebanon. Having an understanding of the experienced can assist the healthcare system in future as well as improving the health of children as they are our future generation.

The aim of this present research was to know the health impacts of children who involved in civils war in Syria and to provide insight into their experiences living with health problems.

\section{Methods}

\section{Study design}

This qualitative study employed ethnography as a study design because it used to describe, discover and/or explore the phenomena (Leininger \& McFarland, 2006). This study was conducted in the Bekaa Valley, Lebanon. This camp was choose because of they received highest number of Syrian refuges which accounted for 365,555 or 39 percent and currently residing in one of the 2564 informal settlements ("Bekaa and Baalbek/Hermel Governorates | OCHA," 2018). Data were collected during interviews. The interviews were conducted in May 2017.

\section{Sampling method}

A purposive sample was used to recruit participants. Purposeful sampling is used because it is cost and time effective sampling method as well as appropriate method for limited number of participants. In additional, it can be effective in exploring anthropological study (Palinkas et al., 2015). 


\section{Inclusion and exclusion criteria}

Participants were eligible if they were mother of children who involved in conflict war. Exclusion criteria included participants with cognitive and physical disability who unable to answer questions. Semi structures face-face interviews took place in community premises. It is an approach in order to elicit wide range of experiences in different contexts and participants variation.

\section{Data collection}

Only the researcher, translator, participants and children were presents during interviewed once. The interviews were lasting for 10 to 15 minutes. Interviews were conducted in English language by researcher and were translated to Arabic local dialect by trained translator. Participants were informed verbally about the study purpose and their participants were voluntary. Each interview began with general and sociodemographic questions and then continues with more specific questions. Participants confidentiality and anonymity were of paramount importance, thus only the research team knew who had participated in the study. Data from ZSA was first summarised and ZSA initially coded and analysed the data. A thematic analysis of the narratives was carried out and was undertaken parallel with the interviews.

\section{Findings}

Ten participants took part in this study. The participants who participate in this study were women and their ages ranged from mid-20s to 40 and their child range from 1 to 15 years old.

The generated themes described a variety of different type of impact on health: Antepartum, intrapartum and postpartum health effects. Table 1 shows the health impact on children.

\section{Antepartum health effects}

Antepartum health effects is defined as any health problems throughout the course of pregnancy ("Prenatal Care,"2019.). Most of the participants agreed about no proper antenatal check-up during pregnancy. If they went for antenatal check-up, no proper schedule ultrasound was done.

"I know that I am refuges and there is no schedule antenatal check-up for me. I make an initiative to go to clinic for proper check-up. Sometimes I need to request for ultrasound. I do this for the seek for my baby ".

( $1^{\text {st }}$ interview)

This lead to various antenatal health problems such as undiagnosed multiple pregnancies, unstable lie, congenital malformation and other medical problems. This problem not just occurs during antenatal period but will affect the whole period of pregnancy.

\section{Intrapartum health effect}

Children suffer arrange of intrapartum health effect. High rates of home delivery as well as birth injury are among intrapartum health effects. Although hospital delivery was common among participants, home delivery was still happen. According the participants, this is due to inaccessible to maternal care and some participants revealed this is due to cultural issues. Even worse, many women were reluctant to give consent for emergency caesarean section even when it indicated.

Even though, they went to the clinic, for a few participants, their children still got birth injury such as hypoxia ischaemic encephalopathy. This is believed due to improper during antenatal check-up and failure to monitor baby for distress and also improper pulling the infant during delivery process. 


\section{Postpartum health effects}

A large theme that emerged from the interviewed was the impact on postpartum health effects, which one participant described as the neurological problems. This is due to continuation from intrapartum health effects. Hydrocephalus, epilepsy, cerebral palsy and spinal bifida are among neurological problems that arise.

Due to disruption of health care and breakdown of societal structures, most of the participants were considered their child having failure to thrive and developmental delayed. They believed that they children undernourished in both macro and micronutrients.

$$
\begin{array}{r}
\text { "My son is undernourished but no one care about it. To make it worse, I don't have } \\
\text { enough money to buy food" } \\
\left(5^{\text {th }} \text { interview }\right)
\end{array}
$$

Several participants spoke about increase risk of communicable disease. Most commonly treated communicable diseases included diarrhoea diseases are common among them. They claimed that most of the time it self-limited. They believed this is due to poor sanitation and overcrowded.

Only one participant spoke about ocular and orthopaedic problem which is based on doctor diagnosis is nystagmus and hip dysplasia, respectively.

"Everyone talks about eyes of my son and it's not funny. This is because eyes of my son constantly moving and he cannot control. I have seen many doctors, but the cost to see specialist doctor is very expansive "

$$
\text { ( } 6^{\text {th }} \text { interview) }
$$

Table 1: Impact of war on health to children

\begin{tabular}{ll}
\hline Themes & Subthemes \\
\hline Antepartum health effects & No proper or misses antenatal check up \\
& No schedule ultrasound \\
& Undiagnosed multiple pregnancy, breech and \\
& other medical problems \\
Intrapartum health effects & Home delivery \\
& Birth injury \\
& Premature delivery \\
Postpartum health effects & Neurological problems - Hydrocephalus, \\
& epilepsy, cerebral palsy, spinal bifida \\
& Developmental delayed \\
& Failure to thrive \\
& Ocular problems- Nystagmus \\
& Orthopaedic problems - Hip dysplasia \\
& Communicable diseases - Diarrhoea \\
\hline
\end{tabular}

The key themes for experience of health problems include: psychological burden, barrier poses by health care systems, disruption of daily living and economic effect (Refer table 2).

Table 2: Summary experience living with health problems

\begin{tabular}{ll}
\hline Themes & Subthemes \\
\hline Psychological burden & Posttraumatic Stress Disorder( PTSD) \\
& Low self-esteem \\
Barrier poses by healthcare system & Double standard \\
& Higher medical bills
\end{tabular}


Disruption of daily living

Economic burden

\author{
Absent from school \\ Literacy rate down \\ Medication and consultation (including OT \\ and physiotherapy) \\ Indirect cost (Transportation, accommodation \\ and etc)
}

Mental health problems among children are common during conflicts but most of it undiagnosed and many of them reluctant to acknowledge their mental health issues. Most of the participants were aware that their children have psychological problems. Based on the conversation, post-traumatic stress disorder ( PTSD) is the most common psychiatry illness which ranging from mild to moderate symptoms. Felt depressed, anxiety and complain of somatic symptoms are among other psychological burden faced by them. Most of the participants stated that they had limited psychological support for their children.

$$
\begin{array}{r}
\text { "I strongly believed that my kid have emotional disturbance due to war but it's } \\
\text { difficult for me to admit it. Sometime she screaming at night and she so scared } \\
\text { when we talked about war" } \\
\left(3^{\text {rd }} \text { interview }\right)
\end{array}
$$

"Because of health problems, my child refuse to go to school because of her friends will talk about her. She also has low self-esteem and likes to be alone" ( $5^{\text {th }}$ interview)

The majority of the participants experienced poses by healthcare systems such as double standard in services. Participants talked about uneven access to health between refuges and local communities and contribute to double standard in getting medical treatment such as long waits times to see medical practitioner and poor staff treatment. This often prevents them from seeking medical treatment. Higher medical bills were another barrier faced by refuges. Those participants who express this issue felt they had to pay more for the medical bills. Having said that, they will generally listen to their physician's advice and instructions.

\section{" The doctor from other clinic said that I no need this medication. This medication is not necessary for me and very pricy" $\left(4^{\text {th }}\right.$ interview)}

Most of the participants talk about disruption of daily living and they looked upset. Because of disruption of daily routines, destruction of their community's school and homes and also limited placements available, the children do not attend formal school even though they know the fundamental and important of education. Some of the participants described due to lack access to education system led to interruption of literacy learning for many children. These findings further underline the negative impact of not attending school.

$$
\begin{array}{r}
\text { "My daughter doesn't have change to go to school. I really pity to her and will } \\
\text { posing a great challenge to her in future. What should I do?" } \\
\text { ( } 7^{\text {th }} \text { interview) }
\end{array}
$$

All of the participants described a significant and constant economic burden that they experienced as a result the health problems. The impact of economic burden was noted in the following statements:

"I don't have money for food,,, so, can you imagine how I want to buy medicine. The medicine are costly, we cannot afford them"

( $8^{\text {th }}$ interview) 
"Money, when I don't have enough money, I will not see the doctor even though my
child gets sick"
$\left(5^{\text {th }}\right.$ interview $)$

As a result of health problems, they need to have money to cover not only concomitant medication cost but also extra costs which include cost of consultation, laboratory and instrument test as well as indirect cost such as transportation, productivity losses and accommodation during treatment. In turn, this will affect adherence to seek a medical care. To making it worse, sometimes they need to pay higher compare to local people.

\section{Discussion}

The interviews highlighted that negative impacts of wars on health of children were many ranging from antepartum to postpartum. In additional, their experienced dealing with health problems varied ranging from psychological to economic burden.

In a conflict zone, antepartum health problems are an important cause of perinatal and maternal morbidity. In particular, the best known example is due to lack of facilities and non-proper antenatal follow up. In order to improves the chances of a health pregnancy, early and regular prenatal care are utmost important. With regular antenatal follow up, this is will reduce risk of pregnancy outcome to the mother and baby in many ways. For example, plan for the pregnancy journey, increase daily intake of folic acid, immunization schedule, control medical problems and also avoid unhealthy behaviours such as smoking, drinking alcohol and etc.

Intrapartum increased risk of congenital abnormality. Past study showed that significant increases in babies born with congenital abnormalities during pre- war period in Sarajevo(Simic et al., 1995). Particular attention during intrapartum period where many children born prematurely. During the war in Croatia in 1991 and 1992, there was increase in preterm delivery rate and decrease in birth weight(Kuvacic, Skrablin, Hodzic, \& Milkovic, 1996).

Post-partum health effects also considers as a critical period for child's health. Children experience various health problems range from physical and psychological which may interfere with daily life. These significant changes will result in decrease in quality of life of children.

Due to various reason such as reduced immunisation coverage, overcrowded, decrease availability of clean water and poor housing in camps area which leads to inadequate sanitation (Shears, Berry, Murphy, \& Nabil, 1987). This facilitates the susceptibility for communicable of disease such as malaria, hepatitis B and C, cholera and tuberculosis. Typically, when immunisation rates fall, herd immunity can break down and lack of innate immunity leading to an increase in the number of vaccine preventable disease. For example, Malaria outbreaks in Afghanistan has been attributed to declining in heard immunity (Rowland, Rab, Freeman, Durrani, \& Rehman, 2002).

Like other conflicts in the world, it is unsurprising that Syrian children refugees may experience many emotions disturbance which make them vulnerable to mental health disorders particularly posttraumatic stress disorder, depression, anxiety. These psychological symptoms may result from stressors including bereavement, displacement, torture and other potentially traumatic events (Steel et al., 2009). This situation is similar with women and children less than five years in Kabul during armed conflict related events in which exposure to traumatic events was significantly associated with PTSD symptoms (Seino, Takano, Mashal, Hemat, \& Nakamura, 2008). A systematic review conducted to determine prevalence of mental disorder among children in conflict area in Middle East such as Israel, Palestine, Lebanon and showed that positive association between prevalence of mental and emotional problems and health related trauma experience (Dimitry, 2012). 
War and conflict are associated with disruption of maternal health services and support and generally accompanied by reduce maternal care. This will further increase maternal and neonatal mortality among refugees. In a study conducted among Afghan refugees in Pakistan revealed that half of deaths among reproductive age women were due pregnancy related due to obstetric emergency (Bartlett et al., 2002).

During conflict, most of the healthcare system has been destroyed including building and infrastructure. Breakdown of public health programs eventually leading to increase communicable diseases. In war countries such as Afghanistan, Congo and Sierra Leone have seen an increase in vector borne diseases such as Malaria, trypanosomiasis and Lassa fever in conjunction with rise in conflict and declined in government health programme (Connolly \& Heymann, 2002)(Bonner et al., 2007)(Rowland et al., 2002). As a common user of healthcare services, children are vulnerable to disruption of healthcare service leading to increases of illness.

Health and economy has a vital health. Hence, health problems can affect both economically and socially to the children. The cost can be direct or indirect cost. Direct cost included cost of consultation, laboratory and instrument, hospitalizations, nursing cost. Meanwhile, indirect cost such as transportation, productivity losses, accommodation during treatment. Another big issues among them is they don't have any form of health insurance to cover they lived.

\section{Conclusion}

Finding from this study emphasized and described the important to know the health effect of war. Heath effect during the war is a wide range of problems affecting as well as on physical, emotional and psychological wellbeing. It also identified a range of factors the suggesting this group of the people who may at risk. In order to prevent or reduce this impact, these present study can serve as a foundation and add additional information related to the issue. So, our task is to work for those movements. In general, it can be concluded that war has great impact on heath among children. The impact on children leads to various experienced. Good health status is considered one of the most important aspects of life.

\section{Acknowledgements}

The authors thank all the participants who shared their experienced with us.

\section{References}

Bartlett, L. A., Jamieson, D. J., Kahn, T., Sultana, M., Wilson, H. G., \& Duerr, A. (2002). Maternal mortality among Afghan refugees in Pakistan, 1999-2000. The Lancet, 359(9307), 643-649. https://doi.org/10.1016/S0140-6736(02)07808-X

Bekaa and Baalbek/Hermel Governorates | OCHA. (n.d.). Retrieved September 4, 2017, from http://www.unocha.org/syrian-arab-republic/syria-crisis-regional-overview/lebanon-countryoffice/bekaa-and-baalbekhermel-g

Bonner, P. C., Schmidt, W.-P., Belmain, S. R., Oshin, B., Baglole, D., \& Borchert, M. (2007). Poor housing quality increases risk of rodent infestation and Lassa fever in refugee camps of Sierra Leone. The American Journal of Tropical Medicine and Hygiene, 77(1), 169-75. Retrieved from http://www.ncbi.nlm.nih.gov/pubmed/17620650

Connolly, M. A., \& Heymann, D. L. (2002). Deadly comrades: war and infectious diseases. Lancet (London, England), $360 \quad$ Suppl, s23-4. Retrieved from http://www.ncbi.nlm.nih.gov/pubmed/12504490

David D, \& J.Kuritsky. (2002). Violent conflict and its impact on health indicators in Sub-Saharan Africa. In Paper presented at the annual meeting ofthe International Studies Association, New Orleans, $L A$. 
Dimitry, L. (2012). A systematic review on the mental health of children and adolescents in areas of armed conflict in the Middle East. Child: Care, Health and Development, 38(2), 153-161. https://doi.org/10.1111/j.1365-2214.2011.01246.x

Fazel, M., Wheeler, J., \& Danesh, J. (2005). Prevalence of serious mental disorder in 7000 refugees resettled in western countries: a systematic review. The Lancet, 365(9467), 1309-1314. https://doi.org/10.1016/S0140-6736(05)61027-6

Goldson, E. (1996). The effect of war on children. Child Abuse \& Neglect, 20(9), 809-19. Retrieved from http://www.ncbi.nlm.nih.gov/pubmed/8886465

Hynes, H. P. (n.d.). On the battlefield of women's bodies: An overview of the harm of war to women. https://doi.org/10.1016/j.wsif.2004.09.001

Kuvacic, I., Skrablin, S., Hodzic, D., \& Milkovic, G. (1996). Possible influence of expatriation on perinatal outcome. Acta Obstetricia et Gynecologica Scandinavica, 75(4), 367-71. Retrieved from http://www.ncbi.nlm.nih.gov/pubmed/8638458

Leininger, M. M., \& McFarland, M. R. (2006). Culture care diversity and universality : a worldwide nursing theory. Jones and Bartlett. Retrieved from https://books.google.co.uk/books/about/Culture_Care_Diversity_Universality.html?id=NmY43 MysbxIC\&redir_esc $=y$

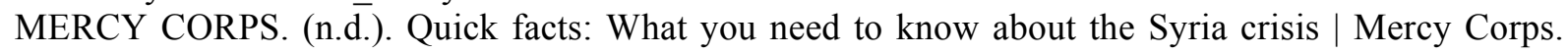
Retrieved September 3, 2017, from https://www.mercycorps.org/articles/iraq-jordan-lebanonsyria-turkey/quick-facts-what-you-need-know-about-syria-crisis

Palinkas, L. A., Horwitz, S. M., Green, C. A., Wisdom, J. P., Duan, N., \& Hoagwood, K. (2015). Purposeful Sampling for Qualitative Data Collection and Analysis in Mixed Method Implementation Research. Administration and Policy in Mental Health, 42(5), 533-44. https://doi.org/10.1007/s10488-013-0528-y

Pearn, J. (2003). Children and war†. Journal of Paediatrics and Child Health, 39(3), 166-172. https://doi.org/10.1046/j.1440-1754.2003.00124.x

Pedersen, D. (2002). Political violence, ethnic conflict, and contemporary wars: broad implications for health and social well-being. Social Science \& Medicine (1982), 55(2), 175-90. Retrieved from http://www.ncbi.nlm.nih.gov/pubmed/12144134

Prenatal Care. (n.d.). Retrieved from https://medlineplus.gov/prenatalcare.html

Richard M. Garfield, \& Alfred I. Neugut. (2000). War and public health / edited by Barry S. Levy, Victor W. Sidel. - Version details - Trove. (American Public Health Association, Ed.). Washington, DC. Retrieved https://trove.nla.gov.au/work/16129252?q\&versionId=26637617

Rowland, M., Rab, M. A., Freeman, T., Durrani, N., \& Rehman, N. (2002). Afghan refugees and the temporal and spatial distribution of malaria in Pakistan. Social Science \& Medicine (1982), 55(11), 2061-72. Retrieved from http://www.ncbi.nlm.nih.gov/pubmed/12406471

Santa Barbara, J. (2006). Impact of war on children and imperative to end war. Croatian Medical Journal, 47(6), 891-4. Retrieved from http://www.ncbi.nlm.nih.gov/pubmed/17167852

Seino, K., Takano, T., Mashal, T., Hemat, S., \& Nakamura, K. (2008). Prevalence of and factors influencing posttraumatic stress disorder among mothers of children under five in Kabul, Afghanistan, after decades of armed conflicts. Health and Quality of Life Outcomes, 6(1), 29. https://doi.org/10.1186/1477-7525-6-29

Shears, P., Berry, A. M., Murphy, R., \& Nabil, M. A. (1987). Epidemiological assessment of the health and nutrition of Ethiopian refugees in emergency camps in Sudan, 1985. British Medical Journal (Clinical Research Ed.), 295(6593), 314-8. Retrieved from http://www.ncbi.nlm.nih.gov/pubmed/3115429

Simic, S., Idrizbegovic, S., Jaganjac, N., Boloban, H., Puvacic, J., Gallic, A., \& Dekovic, S. (1995). Nutritional effects of the siege on new-born babies in Sarajevo. European Journal of Clinical Nutrition, 49 Suppl 2, S33-6. Retrieved from http://www.ncbi.nlm.nih.gov/pubmed/8846763

SIPRI Yearbook 2012: Armaments, Disarmament and International Security, Summary. (n.d.). Retrieved from https://www.sipri.org/sites/default/files/2016-03/SIPRIYB12Summary.pdf

Southall, D., \& Carballo, M. (1996). Can children be protected from the effects of war? BMJ, 313(7070). Retrieved from http://www.bmj.com/content/313/7070/1493

Steel, Z., Chey, T., Silove, D., Marnane, C., Bryant, R. A., \& van Ommeren, M. (2009). Association of Torture and Other Potentially Traumatic Events With Mental Health Outcomes Among 
Populations Exposed to Mass Conflict and Displacement. JAMA, 302(5), 537. https://doi.org/10.1001/jama.2009.1132

WHO | World report on violence and health. (2015). World Health Organization . Retrieved from http://www.who.int/violence_injury_prevention/violence/world_report/en/ 